\title{
International Prognostic Index Risk Group
}

National Cancer Institute

\section{Source}

National Cancer Institute. International Prognostic Index Risk Group. NCI Thesaurus.

Code C161805.

A risk group based on: age (> 60 years); increased serum LDH; ECOG Performance status

$>1$; clinical stage III or IV. 